Original Research Paper

\title{
Forensic Evidence for Cytochrome b Gene SNPs in Obese and Non Obese Saudi Arabians
}

\author{
${ }^{1,2}$ Sayed Amin Mohamed Amer, ${ }^{3}$ Bandar Raddat Allah AlHothali, \\ ${ }^{4}$ Monira Hmoud Alotaibi and ${ }^{5}$ Salah Mohamed Tubaigy \\ ${ }^{I}$ Department of Forensic Biology, College of Forensic Sciences, \\ Naif Arab University For Security Sciences, Riyadh, P.O. 6830, Saudi Arabia \\ ${ }^{2}$ Zoology Department, Faculty of Science, Cairo University, Giza, Egypt \\ ${ }^{3}$ Criminal Evidence Institute, Public Security, Ministry of Interior, Saudi Arabia \\ ${ }^{4}$ Department of Biology, Faculty of Science, Taif University, Taif, Saudi Arabia \\ ${ }^{5}$ Department of Medico Legal Medicine, Ministry of Interior, Riyadh, Saudi Arabia
}

Article history

Received: 28-12-2017

Revised: 19-02-2018

Accepted: 1-03-2018

Corresponding Author: Sayed Amin Mohamed Amer Department of Forensic Biology, College of Forensic Sciences, Naif Arab University For Security Sciences, Riyadh, P.O. 6830, Saudi Arabia

Email: sayed.amer@nauss.edu.sa

\begin{abstract}
Oral swabs from obese and non obese Saudi Arabians from both sexes with an average age of 35 years old were collected and their DNAs were extracted. PCR for $1000 \mathrm{bp}$ of the mitochondrial cytochrome b (cytb) gene was conducted and the amplified products were sequenced in order to determine the possible forensic or obesity-related SNPs. Alignment of the obtained sequences with its counterparts of 100 healthy Afro-Asians deposited in the Genbank was undertaken and the polymorphic sites were compared. Sixteen Single Nucleotide Polymorphic sites (SNPs) and 26 variations were noted. From the 26 variations, sixteen were synonymous and the other 10 were nonsynonymous. Four common haplogroups were determined using Mitomaster software (H2a, JT, U5a and R0a). Most of SNPs were related to tribes more than to obesity and the major SNP (C15452A) was recorded in both obese and non obese haplotypes. Two non-synonymous amino acid changes were found in 2 obese males (H15 and H27; A15043G) and 2 obese females (H48 and H51; C15677A) indicating that both SNPs could be obesity markers. In conclusion, cytb gene is reasonably applicable in forensic purpose while it was unclear to be used as an obesity marker. It needs to be examined for hundreds of unrelated obese and non obese people.
\end{abstract}

Keywords: Cytb, Haplotypes, SNPs, Forensic, Obesity, Saudi Arabia

\section{Introduction}

The hypervariable fragments of mtDNA control region were commonly applied in forensic studies (Monsalve and Hagelberg, 1997; Harihara et al., 1998; Al-Zahery et al., 2011; Hameed et al., 2015) when Short Tandem Repeats (STR) of the nuclear genome are unavailable due to DNA fragmentation and the impossibility of the two-copy DNA markers to persist over time (Gabriel et al., 2001; Tsai et al., 2009).

Cytb gene was used for identification of obese and non obese humans (Demir et al., 2014). The gene has become valuable key for species identification in routine forensic practice too (Lopez-Oceja et al., 2016). Lee et al. (2002) found 30 polymorphic sites distributed along cytochrome b gene in 98 unrelated Koreans. Cytb gene has been also applied in screening polymorphic sites for different human haplotypes based on environmental and geographic implications (Kong et al., 2003; Mishmar et al., 2003). The gene was reported recently to elevate its expression in diabetic people who are possibly nonobese (Carlos et al., 2017). Besides, the cytb gene, the whole mtDNA is also used in identifying mother relatives (Ma et al., 2018) and other forensic caseworks (Eduardoff et al., 2017) which are useful in identifying unknown persons.

On the other hands, obesity induces an increase in the mtDNA content rather than inducing mutation (Alé et al., 2017). Meanwhile, Veronese et al. (2018) correlated the obesity prevalence to certain ethnic Caucasian groups by using the mtDNA data and a recent study used cytb gene in diagnosing obesity (Demir et al., 2014).

Saudi Arabia hosts different human haplogroups among them Saudi population comprising different Arabian tribes. The other haplogroups include the immigrating Asian and African haplotypes. In this study, random individuals from different tribes were collected and the cytb SNPs were recorded to examine variations between the different haplotypes. Unique SNPs for obesity or forensic purposes could be also recorded. 


\section{Materials and Methods}

\section{Samples}

Sixty-six healthy Saudi males (39 obese and 7 non obese) and females (10 obese and 10 non obese) were randomly chosen for this study based on their Body Mass Index (BMI). The ratio of males to females was 69.7 to $30.3 \%$. Criteria for inclusion and exclusion were based on that all samples were healthy with no back or family history disease. Samples with diabetic and blood pressure or cardiovascular diseases were excluded. The BMI of all obese samples were above 30 and samples with BMI between 25 and 30 were excluded. All samples were collected from people who are living in the same geographic region at the western Saudi Arabia. Samples were taken after the agreement of the donors. BMI of the healthy samples was below 25 and above 18. All samples were within the range between 25 to 50 years old. Obese males were numbered from $\mathrm{H} 1$ to $\mathrm{H} 39$ and the healthy ones were numbered from $\mathrm{H} 40$ to $\mathrm{H} 46$. Obese Females were labeled from $\mathrm{H} 47$ to $\mathrm{H} 56$ while healthy females were numbered from H57 to H66.

\section{DNA Extraction}

Wizard ${ }^{\circledR}$ genomic DNA extraction kit (Promega Corporation, Madison, USA) was used for extracting genomic DNA from swab samples according to manufacturer's instructions (www.promega.com/protocols). The concentration of extracted DNA and the extract purity were measured by UV-Vis spectrophotometer at 260/280 nm and DNA was stored in $4^{\circ} \mathrm{C}$ for further use.

\section{Cytb Gene Amplification}

The revised Cambridge reference sequence (Andrews et al., 999) was used to design the forward cytbF: 5'- CCCCAATACGCAAAATTAACCC -3' and the reverse cytbR: 5'GTATAGTACGGATGCTACTTGTC -3 ' primers in order to amplify 1000 bp of cytb gene (nt14747-15887). PCR tube was prepared with a volume of $50 \mu \mathrm{L}$ of $2 \mu \mathrm{L}$ DNA, $2 \mu \mathrm{L}$ of 10 picomolar from the forward and the reverse primers, $25 \mu \mathrm{L}$ PCR master mix (Promega Corporation, Madison, WI) and $19 \mu \mathrm{L}$ autoclaved dd $\mathrm{H}_{2} \mathrm{O}$. PCR was run 5 min with primary denaturation at $94^{\circ} \mathrm{C}$, followed by 35 cycles of denaturation at $94^{\circ} \mathrm{C}$, annealing at $56^{\circ} \mathrm{C}$ and extension at $72^{\circ} \mathrm{C}$ (each for $1 \mathrm{~min}$ ) and finally with post-extension at $72^{\circ} \mathrm{C}$ for $5 \mathrm{~min}$. Amplified products were visualized in gel electrophoresis (1 $\mathrm{g}$ agarose, 1X TAE buffer, ethidium bromide and $100 \mathrm{bp}$ Biolabs DNA ladder). PCR products were purified by spin column (BioFlux, Tokyo, Japan) kit based on the manufacturer's procedure.

\section{Cytb Sequencing}

Sequencing of the purified products was conducted in Applied Biosystems Sequencer (ABI PRISM ABI3730xl) by BigDyeTM Terminator Kits including AmpliTaq-DNA polymerase (FS enzyme). Mitomaster search tool in MitoWeb program (http://mitomap.org/MITOMAP) was used to compare the obtained data with the mtDNA rCRS (Andrews et al., 1999) to search for SNPs and to for haplogroup identification.

\section{Results and Discussion}

Approximately, $1 \mathrm{Kbp}$ of cytb gene was amplified and sequenced in the present study and the data were deposited in the NCBI Genbank database (accession numbers: KT215436-KT215473, KT248511- KT248517 and MG988054-MG988073). Polymorphic sites were determined by comparing all the obtained sequences to the revised Cambridge reference sequence (Andrews et al., 1999). Sixteen SNPs that were noted in at least 2 haplotypes and 26 substitutions were recorded (Table 1). Similar to the finding of Farghadani and Babadi (2015) in Southeast Asian ethnic groups, frequently mutable sites were shown (A15326G, G15301A, G15043A and C15452A). As cytb gene is a protein-coding, mutations were only base substitutions with no deletion or insertion and this substitutions were transitions more than transversion (transition:transversion ratio $=26: 3$ ). Several studies (Tzen et al., 2001; Lee et al., 2009; Farghadani and Babadi, 2015) have revealed similar findings in other human groups.

From 26 changes found in the sequenced fragment among the different haplotypes, 16 were found in the third position of the codon (Table 2) keeping the amino acids unchanged (synonymous) while 10 changes were either in the first or in the second codon positions (non-synonymous) and thus amino acids changed. The sequences of H9, H17 and H34 were different from rCRS (Andrews et al., 1999) in A15326G which could be considered as an obesity marker. The haplotype H19 was different from the reference sequence just in one nucleotide at a position G15148A which was synonymous. Two obese female haplotypes (H48 and H51) showed a unique nonsynonymous position (A15677C, Gln to Lys) which could be considered as an obesity marker since it was recorded only in these two obese females (Table 2). H2a, JT, U5a and R0a were the common recorded haplogroups (Table 3) according to MITOMAP (2018). Each different individual sequence could be assigned to a spate haplogroup since, to the best of our knowledge, no standard for haplogroup identification could be found and thus, 20 haplogroups were recorded. 
Table 1: Sequence variations in cytb gene compared to Andrews sequence. The variations are listed when they were polymorphic (found in more than one individual). The reference stands in bold for Andrews sequence. Numbers on the top indicate nucleotide position in whole mitochondrial genome and dots (.) represent matches with the reference sequence. Haplotypes sharing the same nucleotide at a certain position are listed together

\begin{tabular}{|c|c|c|c|c|c|c|c|c|c|c|c|c|c|c|c|c|}
\hline Sharing haplotypes & 14905 & 15043 & 15218 & 15235 & 15257 & 15262 & 15301 & 15326 & 15431 & 15452 & 15466 & 15607 & 15674 & 15677 & 15679 & 15784 \\
\hline rCRS & $\mathbf{G}$ & G & $\mathbf{A}$ & A & $\mathbf{G}$ & $\mathbf{T}$ & $\mathbf{G}$ & $\mathbf{A}$ & G & $\mathbf{C}$ & $\mathbf{G}$ & $\mathbf{A}$ & $\mathbf{T}$ & $\mathbf{A}$ & $\mathbf{A}$ & $\mathbf{T}$ \\
\hline H6, H33, H65 & A & . & . & . & . & . & . & $\mathrm{G}$ & . & A & . & $\mathrm{G}$ & . & . & . & . \\
\hline H11, H15, H53, H54 & . & A & . & . & . & . & A & G & . & . & . & . & . & . & . & . \\
\hline $\mathrm{H} 8, \mathrm{H} 47$ & . & . & . & $\mathrm{G}$ & . & . & . & G & $\cdot$ & · & . & . & . & . & • & . \\
\hline H15, H27, H49 & . & . & . & . & . & . & . & G & A & . & . & . & . & . & . & . \\
\hline H26, H32 & . & . & G & . & . & . & . & G & . & . & . & . & . & . & . & . \\
\hline $\begin{array}{l}\text { H10, H16, H48, } \\
\text { H51, H61, H66 }\end{array}$ & . & . & . & . & A & . & . & $\mathrm{G}$ & . & A & . & . & . & . & G & . \\
\hline H29, H46 & . & . & . & . & . & $\mathrm{C}$ & . & . & . & . & . & . & . & . & . & . \\
\hline $\begin{array}{l}\text { H1-H3, H5, H8, } \\
\text { H11, H14, H15, } \\
\text { H18, H29, H35-H39, } \\
\text { H40-H42, H46, } \\
\text { H53, H54 }\end{array}$ & . & . & . & . & . & . & A & G & . & . & . & . & . & . & . & . \\
\hline $\begin{array}{l}\text { H4, H6, H10, H16, } \\
\text { H20-H22, H31, } \\
\text { H33, H40, H43-H45, } \\
\text { H48, H51, H55-H57, } \\
\text { H61-H63, H65- H66 }\end{array}$ & . & . & . & . & . & . & . & G & . & $\mathbf{A}$ & · & . & . & · & . & . \\
\hline H31, H40, H55, H57, H60 & . & . & . & . & . & . & . & . & . & . & A & . & . & - & . & . \\
\hline $\mathrm{H} 24, \mathrm{H} 25, \mathrm{H} 28, \mathrm{H} 60$ & . & . & . & . & . & . & . & G & . & . & . & . & $\mathrm{C}$ & . & . & . \\
\hline H48, H51 & . & . & . & . & . & . & . & $\mathrm{G}$ & . & $\mathbf{A}$ & . & . & . & $\mathbf{C}$ & . & . \\
\hline H14, H26, H41, H42 & . & . & . & . & . & . & . & G & . & . & . & . & . & . & . & $\mathrm{C}$ \\
\hline
\end{tabular}

Table 2: Amino acid changes as a result of 26 nucleotide substitutions

\begin{tabular}{|c|c|c|c|c|c|}
\hline $\begin{array}{l}\text { Reference nucleotide } \\
\text { position }\end{array}$ & Substitution & Individuals & Amino acid & $\begin{array}{l}\text { Position in } \\
\text { the codon }\end{array}$ & Synonymous \\
\hline 14905 & G-A & H6, H33, H65 & Met-met & 3 & + \\
\hline 14981 & $\mathrm{~A}-\mathrm{C}$ & $\mathrm{H} 27$ & Ile-Leu & 1 & - \\
\hline 15043 & G-A & H11, H15, H53, H54 & Gly-Gly & 3 & + \\
\hline 15110 & G-A & $\mathrm{H} 18$ & Ala-Thr & 1 & - \\
\hline 15136 & $\mathrm{C}-\mathrm{T}$ & $\mathrm{H} 27$ & Gly-Gly & 3 & + \\
\hline 15148 & G-A & H19 & Pro-Pro & 3 & + \\
\hline 15217 & $\mathrm{G}-\mathrm{A}$ & $\mathrm{H} 18$ & Gly-Gly & 3 & + \\
\hline 15218 & $A-G$ & H26, H32 & Thr-Ala & 1 & - \\
\hline 15229 & $\mathrm{~T}-\mathrm{C}$ & $\mathrm{H} 32$ & Val-Val & 3 & + \\
\hline 15235 & $A-G$ & $\mathrm{H} 8, \mathrm{H} 47$ & Trp-Trp & 3 & + \\
\hline 15257 & G-A & H10, H16, H48, H51, H61, H66 & Asp-Asn & 1 & - \\
\hline 15262 & $\mathrm{~T}-\mathrm{C}$ & $\mathrm{H} 29, \mathrm{H} 46$ & Ser-Ser & 3 & + \\
\hline 15301 & G-A & $\begin{array}{l}\mathrm{H} 1-\mathrm{H} 3, \mathrm{H} 5, \mathrm{H} 8, \mathrm{H} 11, \mathrm{H} 14, \mathrm{H} 15, \mathrm{H} 18, \\
\mathrm{H} 29, \mathrm{H} 35-\mathrm{H} 39, \mathrm{H} 40-\mathrm{H} 42, \mathrm{H} 46, \mathrm{H} 53, \mathrm{H} 54\end{array}$ & Leu-Leu & 3 & + \\
\hline 15326 & $A-G$ & all except $\mathrm{H} 19$ & Thr-Ala & 1 & - \\
\hline 15358 & $A-G$ & H5 & Gly-Gly & 3 & + \\
\hline 15388 & $\mathrm{~T}-\mathrm{C}$ & $\mathrm{H} 29, \mathrm{H} 46$ & His-His & 3 & + \\
\hline 15431 & G-A & $\mathrm{H} 15, \mathrm{H} 27, \mathrm{H} 49$ & Ala-Thr & 1 & - \\
\hline 15452 & $\mathrm{C}-\mathrm{A}$ & $\begin{array}{l}\text { H4, H6, H10, H16, H20-H22, H31, H33, } \\
\text { H40, H43-H45, H47, H50-H53, H55-H56, } \\
\text { H58, H61-H63, H66 }\end{array}$ & Leu-Ile & 1 & - \\
\hline 15466 & G-A & H31, H40, H55, H57, H60 & Met-met & 3 & + \\
\hline 15514 & $\mathrm{~T}-\mathrm{C}$ & $\mathrm{H} 8$ & Tyr-Tyr & 3 & + \\
\hline 15607 & $A-G$ & H6, H33, H65 & Lys-Lys & 3 & + \\
\hline 15674 & $\mathrm{~T}-\mathrm{C}$ & $\mathrm{H} 24, \mathrm{H} 25, \mathrm{H} 28, \mathrm{H} 60$ & Ser-Pro & 1 & - \\
\hline 15677 & $\mathrm{~A}-\mathrm{C}$ & $\mathrm{H} 48, \mathrm{H} 51$ & Gln -Lys & 1 & - \\
\hline 15679 & $A-G$ & H10, H16, H48, H51, H61, H66 & Lys-Lys & 3 & + \\
\hline 15746 & $A-G$ & $\mathrm{H} 13$ & Ile-Val & 1 & - \\
\hline 15784 & $\mathrm{~T}-\mathrm{C}$ & $\mathrm{H} 14, \mathrm{H} 26, \mathrm{H} 41, \mathrm{H} 42$ & Pro-Pro & 3 & + \\
\hline
\end{tabular}


Table 3: Haplogroups and their frequencies in obese samples $(n=49)$. The genetic diversity was calculated according to the formula $\mathrm{D}=\left(1-\Sigma \mathrm{p}^{2}\right)($ Tsai et al., 2009)

\begin{tabular}{lll}
\hline Haplogroup & Number of individuals/haplogroup & Haplogroup frequency \\
\hline H2a & 9 & 0.1840 \\
JT & 7 & 0.1430 \\
U5a & 5 & 0.1020 \\
R0a & 4 & 0.0820 \\
J2a & 3 & 0.0610 \\
T & 3 & 0.0610 \\
L3 & 3 & 0.0610 \\
HV1a & 2 & 0.0410 \\
J1b & 2 & 0.0410 \\
L0a & 1 & 0.0200 \\
L3i & 1 & 0.0200 \\
L3f & 1 & 0.0200 \\
L2b & 1 & 0.0200 \\
L2a & 1 & 0.0200 \\
M30 & 1 & 0.0200 \\
M & 1 & 0.0200 \\
R30b & 1 & 0.0200 \\
B4a & 1 & 0.0200 \\
X2i & 1 & 0.0200 \\
J2b & 1 & 0.0200 \\
Genetic diversity & $1-\Sigma \mathrm{p}^{2}$ & 0.9105 \\
\hline
\end{tabular}

Application of cytb gene in human identification for forensic purposes is questionable since debates between forensic researchers on this marker are found. Farghadani and Babadi (2015) revealed lower efficiency of cytb gene in forensic caseworks than hyper variable regions of the mtDNA control region (Van der Walt et al., 2003; Wong et al., 2007). The authors concluded that the gene is probably not appropriate for routine forensic caseworks. On the other hands, other investigators (Tsai et al., 2009; Hwa et al., 2010; Ablimit et al., 2013) approved forensic efficiency of cytb gene. The present study disagreed with Farghadani and Babadi (2015) since the authors based their conclusion on a small fragment of cytb gene (402 bp), however ours and that of Tsai et al. (2009), Hwa et al. (2010) and Ablimit et al. (2013) were based on nearly the entire gene sequence. Haplogroup frequency in this study ranged between 0.184 and 0.02 (Table 3 ). This frequency is small as the sampling size was small. It could be increased as the sampling size increased. Further study on hundreds of samples is, thus, necessary for wide different Saudi Arabian tribes. Haplogroup frequencies (Table 3) were used to calculate the genetic diversity (Jones, 1972) among the studied haplogroups $(\mathrm{D}=0.9105)$. It was comparable to the genetic distance of the d-loop regions $(\mathrm{D}=0.964)$ calculated by Hameed et al. (2015) and this finding approved the efficiency of cytochrome $b$ gene in forensic investigations.

Regarding obesity, cytb gene diagnosed 2 obese male haplotypes at G15431A. At this position, alanine (Ala) was changed to thrionine (Thr) (non-synonymous) in $\mathrm{H} 15$ and H27. Meanwhile, two obese females H48 and H51 acquired a change of glutamine (Gln) to lysine (Lys) at C15677A. Kobayashi et al. (2011) found similar mutation in different ages Japanese groups suffering from obesity-induced cardiomyopathy. BMI of the abovementioned four obese individuals ranged between 33 and 44.8. We may consider these two positions weak obesity markers since other haplotypes with higher BMI did not exhibit such mutation. Meanwhile, the maternally-related haplotypes, either obese or not, exhibited similar forensic SNPs as shown for $\mathrm{H} 8$ and $\mathrm{H} 41, \mathrm{H} 43$ and H44, H29 and H46 and H20, H21, H22 and H45 (Table 2). We cannot, therefore, neglect the possibility of applying cytb gene in obesity discrimination since very recent study (Veronese et al., 2018) have strongly found a relation between obesity and a certain ethnic group via mtDNA data including cytb gene.

\section{Conclusion}

In conclusion, cytb gene could be used as a forensic marker for Saudi Arabian tribes with a limited resolution; however its application in diagnosing obesity is questionable. The application of this gene in both trends needs more studies on thousands of unrelated obese and non obese humans.

\section{Acknowledgement}

The authors are thankful to all volunteers who donated their swab samples to conduct this study. 


\section{Author's Contributions}

Sayed Amin Mohamed Amer: Constructed the idea, conducted the practical part, wrote the manuscript and followed its publication.

Bandar Raddat Allah AlHothali: Collected the male samples, extracted their DNAs and checked the manuscript writing.

Monira Hmoud Alotaibi: Collected the female samples, extracted their DNAs and conducted PCR experiments.

Salah Mohamed Tubaigy: Supported the work financially, followed the practical part, shared in revising the manuscript and its publication.

\section{Ethics}

The authors declare that they have no competing interests in this study.

\section{References}

Ablimit, A., W. Qin, W. Shan, W. Wu and F. Ling et al., 2013. Genetic diversities of cytochrome B in Xinjiang Uyghur unveiled its origin and migration history. BMC Genet., 14: 100-100.

Alé, A., Y. Zhang, C. Han anAd D. Cai, 2017. Obesityassociated extracellular mtDNA activates central TGF $\beta$ pathway to cause blood pressure increase. Am. J. Physiol. Endocrinol. Metab., 312: E161-E174. DOI: 10.1152/ajpendo.00337.2016

Al-Zahery, N., M. Pala, V. Battaglia, V. Grugni and M.A. Hamod et al., 2011. In search of the genetic footprints of Sumerians: A survey of Ychromosome and mtDNA variation in the Marsh Arabs of Iraq. BMC Evol. Biol., 11: 288-288. DOI: $10.1186 / 1471-2148-11-288$

Andrews, R.M., I. Kubacka, P.F. Chinnery, R.N. Lightowlers and D.M. Turnbul et al., 1999. Reanalysis and revision of the Cambridge reference sequence for human mitochondrial DNA. Nat. Genet., 23: 147-147. DOI: 10.1038/13779

Carlos, D., F.R.C. Costa, C.A. Pereira, F.A. Rocha and J.N.U. Yaochite et al., 2017. Mitochondrial DNA activates the NLRP3 inflammasome and predisposes to type 1 diabetes in murine model. Front. Immunol., 8: 164-164. DOI: 10.3389/fimmu.2017.00164

Demir, D., D. Türkkahraman, A.A. Samur, G. Lüleci and S. Akçurin et al., 2014. Mitochondrial ATPase subunit 6 and cytochrome B gene variations in obese turkish children. J. Clin. Res. Pediatr. Endocrinol., 6: 209-215. DOI: $10.4274 /$ jcrpe. 1601

Eduardoff, M., C. Xavier, C. Strobl, A. CasasVargas and W.R. Parson, 2017. Optimized mtDNA control region primer extension capture analysis for forensically relevant samples and highly compromised mtDNA of different age and origin. Genes, 8: 237-237. DOI: 10.3390/genes8100237
Farghadani, R. and A.A. Babadi, 2015. Nucleotide variation of the mitochondrial cytochrome $\mathrm{B}$ gene in the Malay population. Rom. J. Leg. Med., 23: 57-60. DOI: $10.4323 /$ rjlm.2015.57

Gabriel, M., E. Huffine, J. Ryan, M. Holland and T. Parsons, 2001. Improved mtDNA sequence analysis of forensic remains using a "mini-primer set" amplification strategy. J. Forensic Sci., 46: 247-253. DOI: $10.1520 / J F S 14957 J$

Hameed, I.H., M.A. Gebor and M.A. Kareem, 2015. Forensic analysis of mitochondrial DNA hypervariable region HVII (encompassing nucleotide positions 37 to 340) and HVIII (encompassing nucleotide positions 438-574) and evaluation of the importance of these variable positions for forensic genetic purposes. African J. Biotechnol., 14: 365-374. DOI: 10.5897/AJB2014.14090

Harihara, S., N. Saitou, M. Hirai, T. Gojobori and K. Park et al., 1998. Mitochondrial DNA polymorphism among five Asian populations. Am. J. Hum. Genet., 43: 134-143.

Hwa, H.L., T.M. Ko, Y.C. Chen, Y.Y. Chang and L.H. Tseng et al., 2010. Study of the cytochrome $b$ gene sequence in populations of Taiwan. J. Forensic Sci., 55: 167-170. DOI: $10.1111 /$ j.1556-4029.2009.01195.x

Jones, D.A., 1972. Blood samples: Probability of Discrimination. J. Forensic Sci. Soc., 12: 355-358. DOI: 10.1016/S0015-7368(72)70695-7

Kobayashi, M., S. Nakamura, C. Murakami, K. Maeda and W. Irie et al., 2011. Mutational analysis of the mitochondrial DNA detected in sudden cardiac death caused by cardiomyopathy. Kitasato Med. J., 41: 127-135.

Kong, Q.P., Y.G. Yao, M. Liu, S.P. Shen and C. Chen et al., 2003. Mitochondrial DNA sequence polymorphisms of five ethnic populations from northern China. Hum. Genet., 113: 391-405. DOI: 10.1007/s00439-003-1004-7

Lee, J.C., H.M. Hsieh, L.H. Huang, Y.C. Kuo and J.H. $\mathrm{Wu}$ et al., 2009. Ivory identification by DNA profiling of cytochrome $b$ gene. Int. J. Legal Med., 123: 117-121. DOI: 10.1007/s00414-008-0264-0

Lee, S.D., Y.S. Lee and J.B. Lee, 2002. Polymorphism in the mitochondrial cytochrome B gene in Koreans: An additional marker for individual identification. Int. J. Legal Med., 116: 74-78. DOI: $10.1007 / \mathrm{s} 004140100238$

Lopez-Oceja, A., D. Gamarra, S. Borragan, S. Jiménez-Moreno and M.M. de Pancorbo, 2016. New cyt $b$ gene universal primer set for forensic analysis. Forensic Sci. Int. Genet., 23: 159-165. DOI: $10.1016 /$ j.fsigen.2016.05.001 
Ma, K., X. Zhao, H. Li, Y. Cao and W. Li et al., 2018. Massive parallel sequencing of mitochondrial DNA genomes from mother-child pairs using the ion torrent Personal Genome Machine (PGM). Forensic Sci. Int. Genet., 32: 88-93. DOI: $10.1016 /$ j.fsigen.2017.11.001

Mishmar, D., E. Ruiz-Pesini, P. Golik, V. Macaulay and A.G. Clark et al., 2003. Natural selection shaped regional mtDNA variation in humans. Proc. Nat. Acad. Sci. USA, 100: 171-176.

DOI: $10.1073 /$ pnas. 0136972100

MITOMAP, 2018. A human mitochondrial genome database. [http://www.mitomap.org]

Monsalve, M. and E. Hagelberg, 1997. Mitochondrial DNA polymorphisms in Carib people of Belize. Proc. R. Soc. Lond. B Biol. Sci., 264: 1217-1224. DOI: $10.1098 / \mathrm{rspb} .1997 .0168$

Tsai, L.C., J.C.I. Lee, A.C.Y. Lin, C.H. Su and S.J. Chen et al., 2009. Analysis of the cytochrome b gene in Taiwanese populations. Forensic Sci. J., 8: 29-34.
Tzen, C.Y., T.Y. Wu and H.F. Liu, 2001. Sequence polymorphism in the coding region of mitochondrial genome encompassing position 8389-8865. Forensic Sci. Int., 120: 204-209.

Van der Walt, J.M., K.K. Nicodemus, E.R. Martin, W.K. Scott and M.A. Nance et al., 2003. Mitochondrial polymorphisms significantly reduce the risk of Parkinson disease. Am. J. Hum. Genet., 72: 804-811. DOI: $10.1086 / 373937$

Veronese, N., B. Stubbs, A. Koyanagi, A. Vaona and J. Demurtas et al., 2018. Mitochondrial genetic haplogroups and incident obesity: A longitudinal cohort study. Eur. J. Clin. Nut. DOI: 10.1038/s41430-018-0097-y

Wong, H.Y., J.S.W. Tang, B. Budowle, M.W. Allard and C.K.C. Syn et al., 2007. Sequence polymorphism of the mitochondrial DNA hypervariable regions I and II in 205 Singapore Malays. Leg. Med. (Tokyo), 9: 33-37.

DOI: 10.1016/j.legalmed.2006.08.007 